\title{
Clinical characteristics, treatment outcomes and potential novel therapeutic options for patients with neuroendocrine carcinoma of the prostate
}

\author{
Leonidas Apostolidis ${ }^{1}$, Cathleen Nientiedt ${ }^{1}$, Eva Caroline Winkler ${ }^{1}$, Anne Katrin \\ Berger $^{1}$, Clemens Kratochwil ${ }^{2}$, Annette Kaiser ${ }^{3}$, Anne-Sophie Becker ${ }^{3}$, Dirk Jäger ${ }^{1}$, \\ Markus Hohenfellner ${ }^{4}$, Clemens Hüttenbrink ${ }^{5}$, Sascha Pahernik ${ }^{5}$, Florian A. \\ Distler ${ }^{5, *}$ and Carsten Grüllich ${ }^{1, *}$ \\ ${ }^{1}$ Department of Medical Oncology, National Center for Tumor Diseases, University Hospital Heidelberg, Heidelberg, Germany \\ ${ }^{2}$ Department of Nuclear Medicine, University Hospital Heidelberg, Heidelberg, Germany \\ ${ }^{3}$ Institute of Pathology, Klinikum Nuremberg, Paracelsus Medical University, Nuremberg, Germany \\ ${ }^{4}$ Department of Urology, University Hospital Heidelberg, Heidelberg, Germany \\ ${ }^{5}$ Department of Urology, Klinikum Nuremberg, Paracelsus Medical University, Nuremberg, Germany \\ *These authors have contributed equally to this work \\ Correspondence to: Leonidas Apostolidis, email: leonidas.apostolidis@med.uni-heidelberg.de \\ Keywords: neuroendocrine carcinoma; neuroendocrine tumor; carcinoid; prostate; chemotherapy \\ Received: September 19,2018 Accepted: December 10,2018 Published: January 01, 2019 \\ Copyright: Apostolidis et al. This is an open-access article distributed under the terms of the Creative Commons Attribution License \\ 3.0 (CC BY 3.0), which permits unrestricted use, distribution, and reproduction in any medium, provided the original author and \\ source are credited.
}

\section{ABSTRACT}

Background: Neuroendocrine carcinomas of the prostate (NEPCs) are rare tumors with poor prognosis. While platinum and etoposide-based chemotherapy regimens $(P E)$ are commonly applied in first-line for advanced disease, evidence for second-line therapy and beyond is very limited.

Methods: Retrospective analysis of all patients with NEPCs including mixed differentiation with adenocarcinoma component and well differentiated neuroendocrine tumors (NETs, carcinoids) at two high-volume oncological centers between $12 / 2000$ and $11 / 2017$.

Results: Of 46 identified patients $39.1 \%$ had a prior diagnosis of prostatic adenocarcinoma only, $43.5 \%$ had a mixed differentiation at NEPC diagnosis, $67.4 \%$ developed visceral metastases, $10.9 \%$ showed paraneoplastic syndromes. Overall survival (OS) from NEPC diagnosis was 15.5 months, and significantly shorter in patients with a prior prostatic adenocarcinoma $(5.4$ vs. 32.7 months, $p=0.005) .34$ patients received palliative first-line systemic therapy with a median progressionfree survival (PFS) of $\mathbf{6 . 6}$ months, mostly PE. Overall response rate (ORR) for PE was $48.1 \% .19$ patients received second-line therapy, mostly with poor responses. Active regimens were topotecan (1 PR, 3 PD), enzalutamide (1 SD), abiraterone (1 SD), FOLFIRI (1 SD), and ipilimumab+nivolumab (1 PR). One patient with prostatic carcinoid was sequentially treated with octreotide, peptide receptor radionuclide therapy and everolimus, and survived for over 9 years.

Conclusions: EP in first-line shows notable ORR, however limited PFS. For secondline therapy, topotecan, FOLFIRI, enzalutamide, abiraterone and immune checkpoint blockade are treatment options. Prostatic carcinoids can be treated in analogy to well differentiated gastrointestinal NETs. 


\section{INTRODUCTION}

Neuroendocrine Carcinoma (NEC) of the prostate (NEPC) is considered a rare tumor entity with a rising incidence [1]. Compared to conventional adenocarcinoma, NEPC is characterized by an aggressive tumor biology with loss of PSA secretion, unresponsiveness to androgen deprivation therapy (ADT), development of visceral metastases and limited prognosis [2]. NEPC can feature an adenocarcinoma component, resulting in a mixed differentiation. Besides NEPC arising de novo, more commonly they are described in the context of castrationresistant prostate cancer after ADT.

Compared to adenocarcinoma, prognosis of NEPC is poor with survival ranging from 7 to 10 months. Due to the rarity of the disease, the optimal treatment strategy is up to debate. Like in NECs of other organ systems, platinum-based chemotherapy regimens are commonly applied in first-line for advanced disease [3-9]. Despite encouraging response rates in several phase II studies, progression-free (PFS) and overall survival (OS) are short. Clinical-grade evidence for systemic treatment options in second-line and beyond is extremely limited $[3,10,11]$.

On the other hand, well differentiated Neuroendocrine Tumors (NETs, carcinoids) of the prostate are even rarer than highly proliferative NEPCs with only few reported cases in the literature $[12,13]$. While the biology is more indolent than in poorly differentiated NEPC, response to chemotherapy is generally poor [14]. Treatment with somatostatin analogues, targeted agents and peptide receptor radionuclide therapy (PRRT) is considered standard of care for NETs of the gastrointestinal tract [15] but has not been evaluated in prostatic NETs (carcinoids) so far.

The aim of our study was to investigate the clinical characteristics and treatment outcome of patients with NEPC.

\section{RESULTS}

\section{Patient characteristics}

A total of 46 male patients with a median age of 69 years were identified (Table 1). Median follow-up was 61.0 months. $39.1 \%$ of patients had a prior diagnosis of prostatic adenocarcinoma only, the median interval between adenocarcinoma and NEPC diagnosis was 28.2 months (range 1.0-123.8). 20 men (43.5\%) showed a mixed differentiation at NEPC diagnosis. Small cell histology was documented in $45.7 \%$ of patients. Median proliferation rate (Ki67) was $80 \%$. 1 Patient with nonsmall cell histology was classified as carcinoid (well differentiated NET) with a Ki67 of only $1 \% .8$ patients $(17.4 \%)$ were diagnosed in a localized stage. The remaining $82.6 \%$ of patients $(75.0 \%$ with de-novo NEPC, $94.4 \%$ with prior adenocarcinoma) were diagnosed with synchronous metastatic NEPC, with $67.4 \%$ developing visceral (i.e. non-bone, non-lymphatic) metastases and $65.2 \%$ developing bone metastases during the course of the disease. Median tumor marker levels were $3.2 \mathrm{x}$ ULN (upper limit normal) for PSA, $6.1 \times$ ULN (i.e. $518.0 \mathrm{ng} /$ $\mathrm{ml}$ ) for chromogranin A and $7.6 \mathrm{x}$ ULN (i.e. $128.5 \mathrm{ng} /$ $\mathrm{ml}$ ) for NSE (neuron-specific enolase). $10.9 \%$ of patients showed paraneoplastic syndromes, including 1 case of paraneoplastic neuropathy, 1 case of disseminated intravasal coagulation, 1 case of ectopic ACTH (adrenocorticotropic hormone) production and 2 cases of SIADH (syndrome of inappropriate antidiuretic hormone secretion).

\section{Survival}

Median OS from the timepoint of diagnosis of any prostatic malignancy was 32.1 months, from the timepoint of NEPC diagnosis it was 15.5 months (Figure 1) with 6-month survival rate of 0.76 (95\% CI 0.63-0.87) and 12 -month survival rate of 0.57 (95\% CI 0.41-0.73). In a univariate analysis of OS in different subgroups, patients with previous history of prostatic adenocarcinoma had a significantly worse prognosis (5.4 vs. 32.7 months, $\mathrm{p}=0.005)$ (Table 2, see Supplementary Table 1 for 6-month and 12-month survival proportion estimates). There was no significant difference in OS of patients with mixed vs. purely neuroendocrine differentiation. Patients with elevated levels of lactate dehydrogenase (LDH) showed a strong trend towards a shortened OS of 5.4 vs. 17.3 months $(p=0.064)$. For patients with metastatic disease not receiving any palliative systemic therapy for NEPC, median OS was 3.9 months.

\section{Efficacy of first-line therapy}

34 patients received palliative first-line systemic therapy, mostly platinum and etoposide (PE) $(n=27)$. A median of 5 cycles of PE was administered (range 1-9). Median PFS was 6.6 months (Figure 2). Overall response rate (ORR) for PE was $48.1 \%$ (1 complete response [CR], 12 partial responses [PR], 1 stable disease [SD]). ORR was higher in patients with small cell vs. non-small cell histology (56.3\% vs. $36.4 \%$ ), however similar in patients with mixed vs. pure neuroendocrine differentiation ( 45.5 vs. $50.0 \%$ ). Of the patients receiving PE, 10 patients were treated with cisplatin and 12 patients received carboplatin. 5 patients switched from cisplatin to carboplatin because of toxicity after a median of 2 cycles. Patients primarily treated with carboplatin showed a trend towards a prolonged PFS of 7.5 months vs. those receiving cisplatin (3.9 months, $\mathrm{p}=0.114$ ) (Figure $3 \mathrm{~A}$ ). PFS for patients who switched to carboplatin was similar to those who only received cisplatin (3.9 months). Only 3 Patients with proliferation rate (Ki67) of $<55 \%$ were treated with PE. They showed a strong trend towards 
Table 1: Patient characteristics at NEPC diagnosis

\begin{tabular}{|c|c|c|c|c|}
\hline & & & Number of patients $N=46$ & $\%$ \\
\hline \multirow[t]{2}{*}{ Age [years] } & Median & 69 & & \\
\hline & Range & $51-82$ & & \\
\hline \multirow[t]{2}{*}{ Stage } & Localized & & 8 & 17.4 \\
\hline & Metastatic & & 38 & 82.6 \\
\hline \multirow[t]{9}{*}{ Metastatic sites } & Lymph nodes & & 34 & 73.9 \\
\hline & Bone & & 30 & 65.2 \\
\hline & Liver & & 20 & 43.5 \\
\hline & Lung & & 14 & 30.4 \\
\hline & Brain & & 8 & 17.4 \\
\hline & Pleura & & 3 & 6.5 \\
\hline & Adrenal gland & & 2 & 4.3 \\
\hline & Peritoneum & & 3 & 6.5 \\
\hline & Other & & 4 & 8.7 \\
\hline Paraneoplastic & SIADH & & 2 & 4.3 \\
\hline \multirow[t]{3}{*}{ syndromes } & Ectopic ACTH production & & 1 & 2.2 \\
\hline & Neuropathy & & 1 & 2.2 \\
\hline & DIC & & 1 & 2.2 \\
\hline \multirow[t]{4}{*}{ Ki67 [\%] } & Median & 90 & & \\
\hline & Range & $1-100$ & & \\
\hline & $<55$ & & 9 & 19.6 \\
\hline & $\geq 55$ & & 25 & 54.3 \\
\hline \multirow[t]{4}{*}{ Histology } & Small cell & & 21 & 45.7 \\
\hline & Non small cell & & 25 & 54.3 \\
\hline & Mixed differentiation & & 20 & 43.5 \\
\hline & Carcinoid & & 1 & 2.2 \\
\hline Prior prostatic adenocarcinoma & & & 18 & 39.1 \\
\hline \multirow[t]{8}{*}{ Tumor markers } & PSA $>$ ULN & & 26 & 56.5 \\
\hline & $\mathrm{PSA} \leq \mathrm{ULN}$ & & 6 & 13.0 \\
\hline & $\mathrm{NSE}>\mathrm{ULN}$ & & 21 & 45.7 \\
\hline & $\mathrm{NSE} \leq \mathrm{ULN}$ & & 3 & 6.5 \\
\hline & $\mathrm{CgA}>\mathrm{ULN}$ & & 12 & 26.1 \\
\hline & $\mathrm{CgA} \leq \mathrm{ULN}$ & & 3 & 6.5 \\
\hline & $\mathrm{LDH}>\mathrm{ULN}$ & & 13 & 28.3 \\
\hline & $\mathrm{LDH} \leq \mathrm{ULN}$ & & 18 & 39.1 \\
\hline \multirow[t]{8}{*}{ Therapy prior to NEPC diagnosis } & Surgery of primary & & 19 & 41.3 \\
\hline & Radiotherapy of primary & & 9 & 19.6 \\
\hline & Androgen deprivation therapy & & 17 & 27.0 \\
\hline & Abiraterone & & 4 & 8.7 \\
\hline & Enzalutamide & & 3 & 6.5 \\
\hline & Docetaxel & & 6 & 13.0 \\
\hline & Cabazitaxel & & 2 & 4.3 \\
\hline & PSMA radionuclide therapy & & 1 & 2.2 \\
\hline
\end{tabular}


A

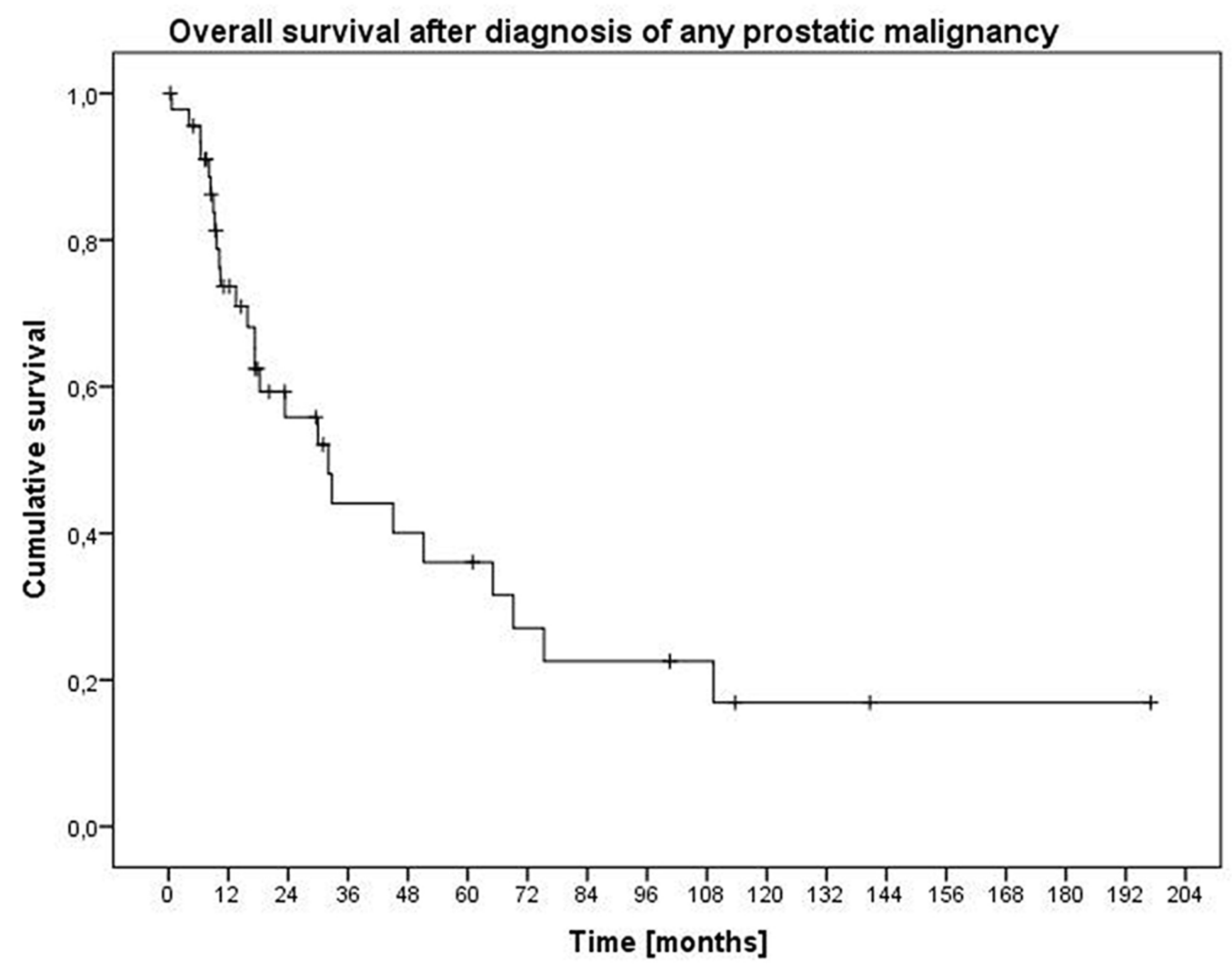

B

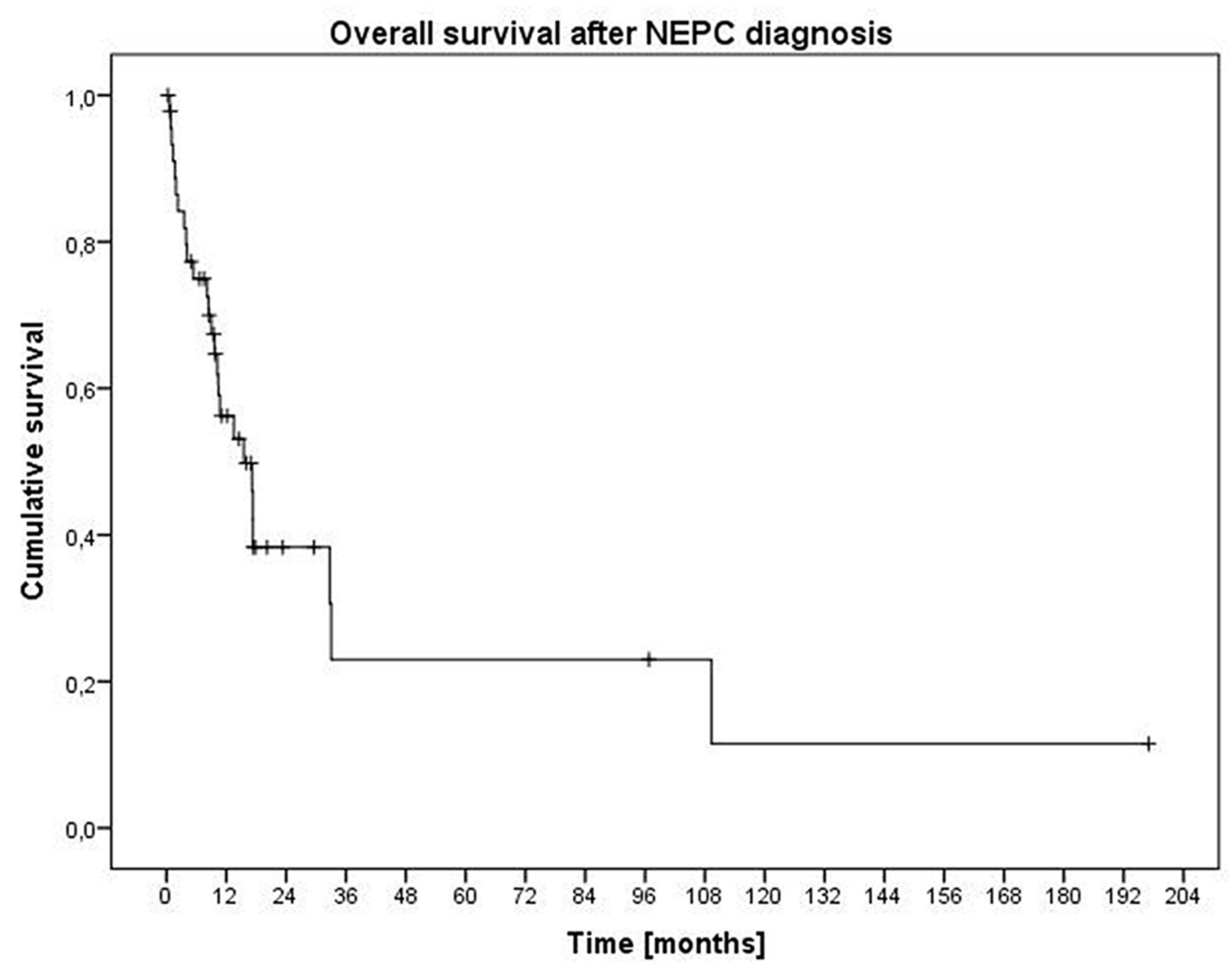

Figure 1: Overall survival from diagnosis of any prostatic malignancy (A) and from diagnosis of NEPC (B). 
Table 2: Overall survival from the timepoint of NEPC diagnosis in different subgroups

\begin{tabular}{|c|c|c|c|}
\hline & & Median OS [months] & $\mathbf{p}$ \\
\hline \multirow[t]{2}{*}{ Histology } & Small cell & 15.5 & 0.828 \\
\hline & Non-small cell & 17.1 & \\
\hline \multirow[t]{2}{*}{ Mixed differentiation } & Yes & 15.5 & 0.970 \\
\hline & No & 17.3 & \\
\hline \multirow[t]{2}{*}{ Prior adenocarcinoma } & Yes & 5.4 & 0.005 \\
\hline & No & 32.7 & \\
\hline \multirow[t]{2}{*}{ Ki67 } & $\geq 55 \%$ & 10.4 & 0.325 \\
\hline & $<55 \%$ & 17.1 & \\
\hline \multirow[t]{2}{*}{ PSA } & $>\mathrm{ULN}$ & 10.7 & 0.719 \\
\hline & $\leq \mathrm{ULN}$ & 33.1 & \\
\hline \multirow[t]{2}{*}{ NSE } & $>\mathrm{ULN}$ & 9.6 & 0.105 \\
\hline & $\leq \mathrm{ULN}$ & NR & \\
\hline \multirow[t]{2}{*}{$\mathrm{CgA}$} & $>\mathrm{ULN}$ & 15.5 & 0.330 \\
\hline & $\leq \mathrm{ULN}$ & 9.6 & \\
\hline \multirow[t]{2}{*}{ LDH } & $>\mathrm{ULN}$ & 5.4 & 0.064 \\
\hline & $\leq \mathrm{ULN}$ & 17.3 & \\
\hline \multirow[t]{2}{*}{ Stage } & Localized & 32.7 & 0.411 \\
\hline & Metastatic & 15.5 & \\
\hline \multirow[t]{2}{*}{ Visceral metastases } & Yes & 13.5 & 0.166 \\
\hline & No & NR & \\
\hline \multirow[t]{2}{*}{ Palliative systemic therapy } & Yes & 17.4 & 0.192 \\
\hline & No & 3.9 & \\
\hline
\end{tabular}

a lower PFS of 1.9 months vs. patients with a Ki67 $\geq$ $55 \%$ (5.6 months, $\mathrm{p}=0.071$, Figure $3 \mathrm{~B}$ ). Of patients who received another first-line therapy than PE, only 6 were evaluable for response, $1 \mathrm{PD}$ with docetaxel, $1 \mathrm{SD}$ and 1 PR with FOLFIRI, 1 SD with abiraterone, 1 SD with enzalutamide. The sixth patient was treated with the somatostatin analogue octreotide for his well differentiated NET (carcinoid), which resulted in a disease stabilization for 31.1 months.

\section{Second-line therapy and beyond}

19 patients received second-line therapy, mostly with poor response rates (Table 3 ).

Beside PE, regimens with notable activity were topotecan, enzalutamide, and FOLFIRI. Most notably, 1 patient primary refractory to PE showed a very good PR under dual immune checkpoint blockade with ipilimumab+nivolumab for more than 6 months (Figure 4). The patient with the prostatic carcinoid showed prolonged disease stabilization for 37.9 months under PRRT targeting the somatostatin receptor.
Third-line therapy was applied to 6 patients only. Of those, only the carcinoid patient showed disease stabilization under everolimus, 1 patient showed a CR to re-exposition with PE. The patient treated with ipilimumab+nivolumab showed a progressive bone metastasis after 7.1 months under nivolumab maintenance therapy. Upon reinduction with ipilimumab, immunotherapy had to be stopped due to a grade 3 autoimmune colitis after the first cycle. After palliative bone radiotherapy, he received enzalutamide which resulted in short-term disease stabilization. The other 3 patients showed PD (1x FOLFIRI, 1x docetaxel, 1x carboplatin+paclitaxel).

The carcinoid patient received a salvage PRRT with an alpha emitter, the therapy had to be discontinued due to progressive bone marrow carcinosis and increasing bone marrow insufficiency. Finally, he died from progressive disease 109.3 months after NET diagnosis. The sequence of systemic therapies and chromogranin A levels are summarized in Figure 5. 


\section{DISCUSSION}

The clinical characteristics of our NEPC patient cohort are in line with previous reports, including the frequent presence of visceral metastases and paraneoplastic syndromes, as well as elevated neuroendocrine tumor markers (chromogranin A, NSE) $[2,16]$. The worse prognosis of patients with a prior history of adenocarcinoma can be most likely explained by the several lines of systemic therapies those patients have already received for adenocarcinoma when they are diagnosed with NEPC, leading to a selection of a more resistant disease. On the other hand, the similar behavior of patients with pure neuroendocrine and mixed adeno-neuroendocrine differentiation (regarding OS and response to first-line therapy) might indicate that the neuroendocrine component seems to be the main prognostic driver of the disease regardless of a coexisting adenocarcinoma component.

Platinum and etoposide-based chemotherapy is considered standard of care for high grade NEC in different locations, including lung and gastrointestinal tract [17]. Several phase II trials have examined platinumbased combination treatments in NEPC [3-9]. The trials are difficult to compare since in some histological proof for NEPC was mandatory, whereas others recruited also patients with only clinical features suggestive for NEPC. However, response rates and survival were not considerably higher in trials examining a platinum-based combination therapy employing 3 agents compared to those with 2 agents. In general, both cisplatin and carboplatin-based chemotherapy regimens are considered equally effective in NEC [17]. However, in our study there was a slight trend for a prolonged PFS with carboplatin. This may be due to a selection bias in our small retrospective cohort. Additionally, the toxicity profile of cisplatin might contribute to more frequent treatment interruptions and delays in an elderly patient population. Patients with a lower Ki67 of $<55 \%$ showed a strong trend for a shortened PFS under PE, this difference failed to reach significance most likely due to the small patient numbers in this group. This phenomenon has

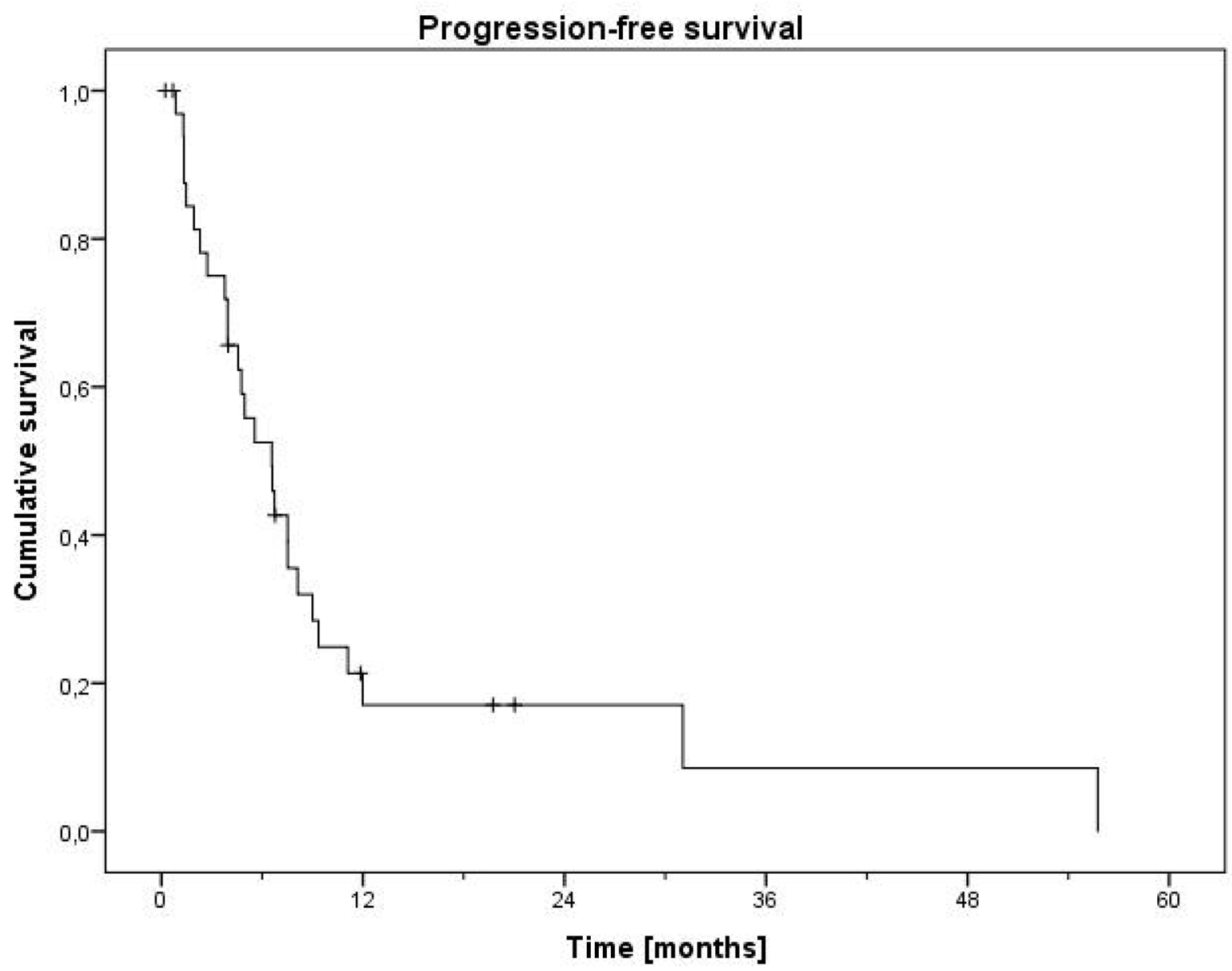

Figure 2: Progression-free survival of first-line therapy. 
A

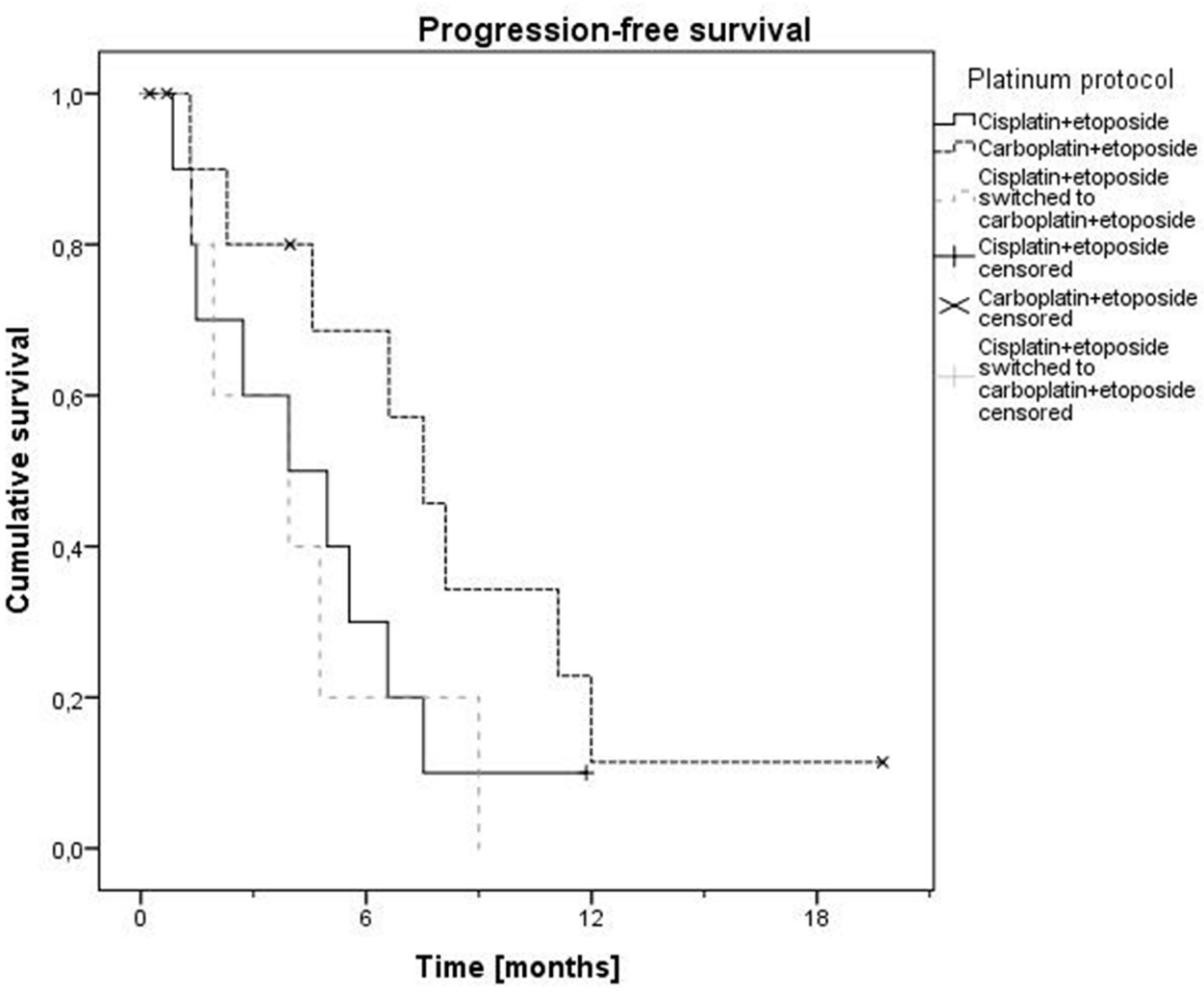

B

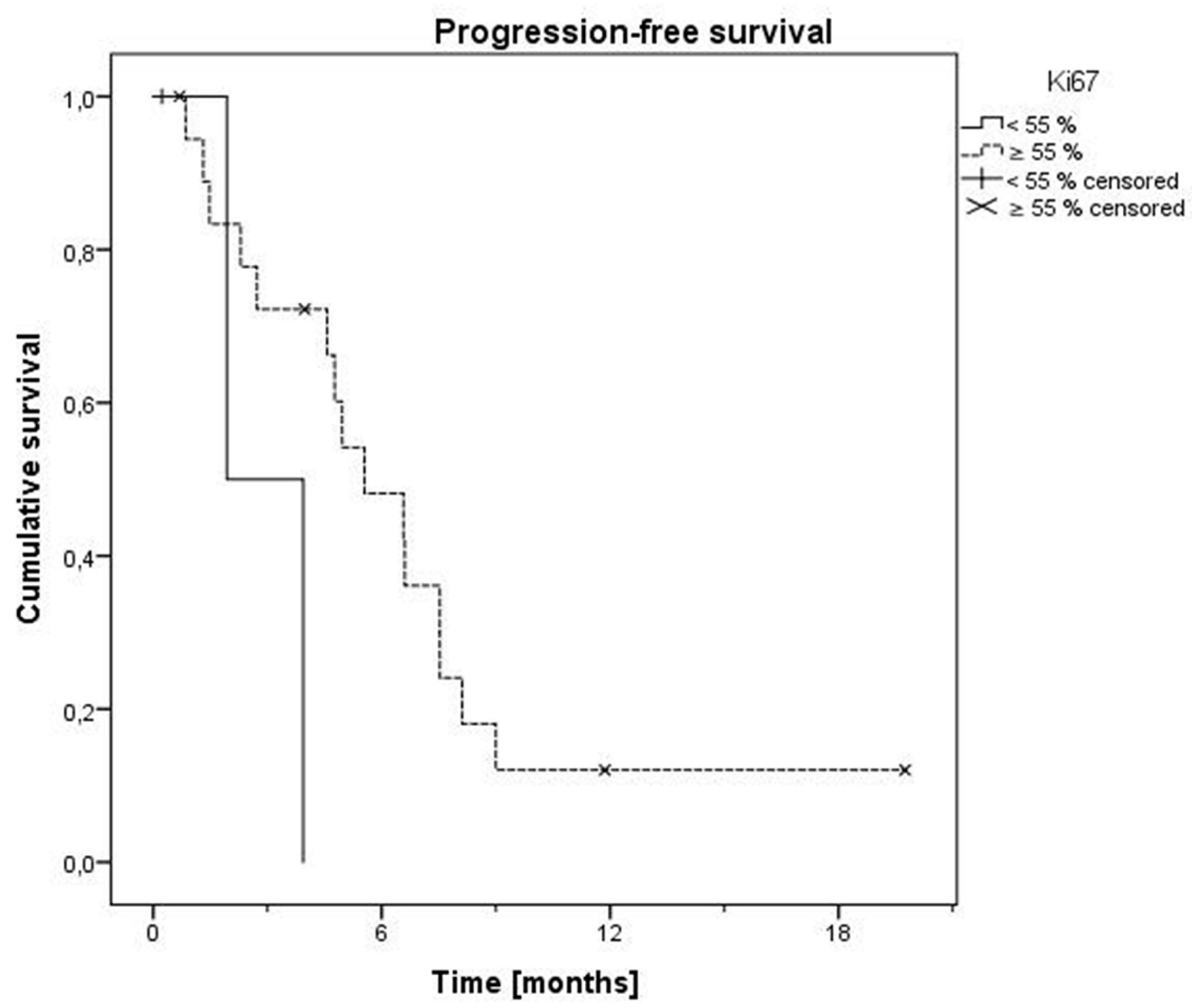

Figure 3: Progression-free survival for platinum and etoposide regarding type of platinum (A) and Ki67 ( $\geq 55 \%$ vs. $<55 \%$ ) (B). 
Table 3: Overview of second-line therapies

\begin{tabular}{|c|c|c|c|c|c|c|c|}
\hline & Total & CR & $\mathbf{P R}$ & SD & PD & NE & $\begin{array}{c}\text { median DoR } \\
\text { [months] (for CR, } \\
\text { PR, SD) }\end{array}$ \\
\hline PE & 5 & & 3 & 1 & & 1 & 8.0 \\
\hline Topotecan & 5 & & 1 & & 3 & 1 & 5.9 \\
\hline FOLFIRI & 1 & & & 1 & & & 8.4 \\
\hline FOLFOX & 1 & & & & 1 & & \\
\hline Docetaxel & 1 & & & & & 1 & \\
\hline Enzalutamide & 1 & & & 1 & & & 8.1 \\
\hline Abiraterone & 1 & & & & & 1 & \\
\hline Everolimus & 1 & & & & 1 & & \\
\hline PRRT & 1 & & 1 & & & & 37.5 \\
\hline SIRT & 1 & & & & 1 & & \\
\hline Ipilimumab+nivolumab & 1 & & 1 & & & & 7.1 \\
\hline
\end{tabular}

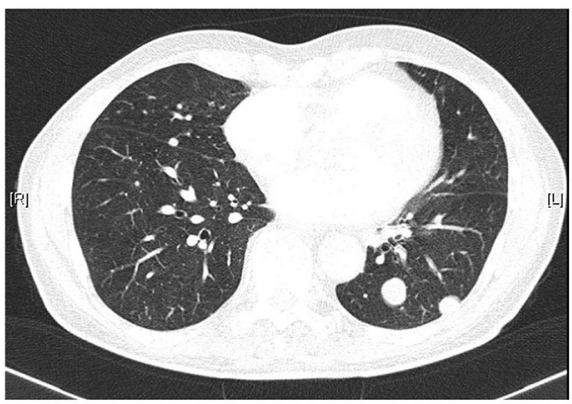

$12 / 2016$

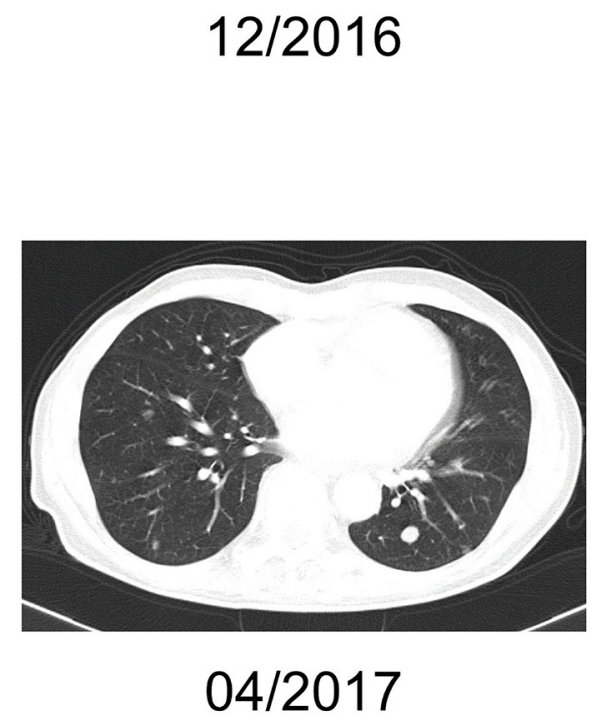

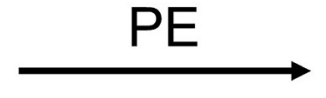

Nivolumab
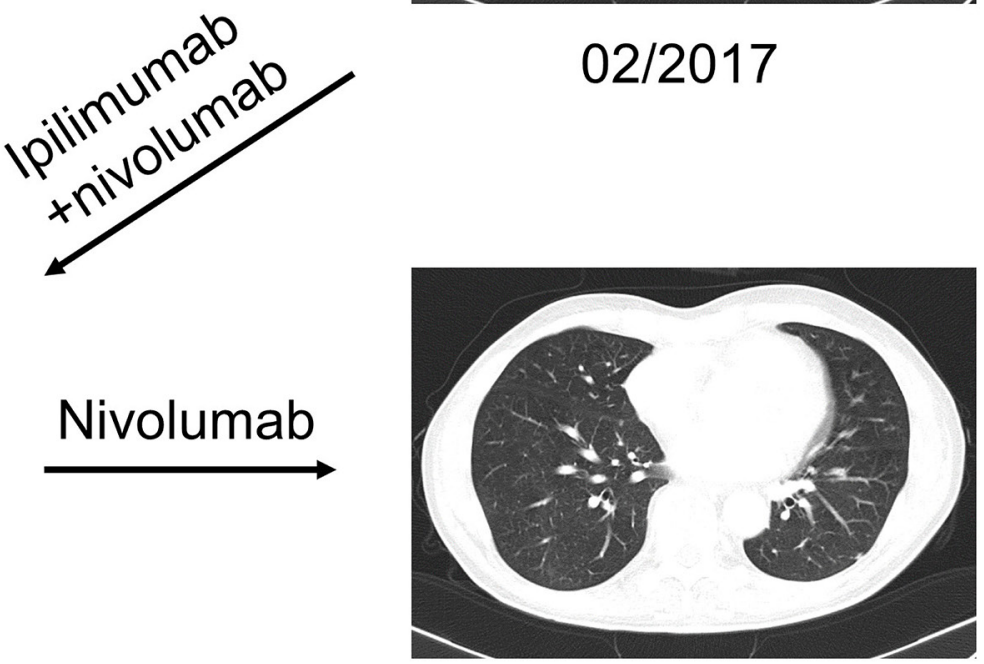

$10 / 2017$

Figure 4: Case example of sustained partial remission to immune checkpoint blockade. CT scans of a 70-year old patient with small cell NEPC with minor adenocarcinoma component, Ki67 $85 \%$. After direct progression to PE, the patient was treated with 4 cycles of dual immune checkpoint blockade with ipilimumab+nivolumab, following nivolumab maintenance therapy. He showed a very good PR for more than 6 months. 
already been described in several retrospective analyses of NEC of the gastrointestinal tract [18-20], and finally led to a newly defined tumor entity of well differentiated neuroendocrine tumors grade 3 (NET G3) which has been officially introduced with the World Health Organization Classification of Tumors of Endocrine Organs of 2017. Current treatment guidelines recommend alternative treatment protocols to PE for NET G3 which have shown notable activity in second-line after PE failure [17, 21, 22], but have not been evaluated in first-line situation yet. The entity of NET G3 has not been established in NEPC so far.

Regarding second-line therapy or alternatives to platinum-based chemotherapy, evidence for NEPC is very scarce. One of the above-mentioned studies applied second-line therapy with cisplatin and etoposide after progression to the first-line treatment with carboplatin and docetaxel [3]. Combination therapy of doxorubicin, cyclophosphamide and vincristine [9] as well as amrubicin monotherapy [23] showed some activity in small case series. Molecular alterations in NEPCs have been extensively studied. Besides alterations common to prostatic adenocarcinoma like TMPRSS2-ERG fusion and alterations in DNA damage repair proteins (e.g. BRCA1, BRCA2, FANCA), several genes have been identified specific for neuroendocrine transdifferentiation, like TP53, RB1, AURKA (Aurora Kinase A), MYCN, and MTOR [24-30]. A comprehensive genomic characterization of treatment related NEPC, reported further transcriptomic markers like PDX1, EZH2, BRN2, FOXA2 and ASCL1 [31]. Recently, a phase II trial with the AURKA inhibitor alisertib was presented with a median PFS of 8.7 weeks [11]. Although it failed to meet its primary endpoint with a 6-month PFS of only $12.6 \%, 3$ of 59 patients showed exceptional remissions or disease stabilizations. In a preliminary retrospective analysis of 7 patients treated with the MTOR inhibitor everolimus a decrease in tumor markers was noted in 5 patients [10]. In our analysis, the single patient receiving everolimus for highly proliferative NEPC showed PD; however, a disease stabilization and tumor marker decrease was noted in the patient with well differentiated NET (carcinoid).

Regarding the limited evidence, second-line treatments recommended for non-prostatic NEC can also be considered an option for NEPC. Topotecan is a standard of care therapy for small cell NEC of the lung [32]. However, the activity of topotecan in extrapulmonary NEC is very limited $[33,34] .1$ of 4 patients treated with

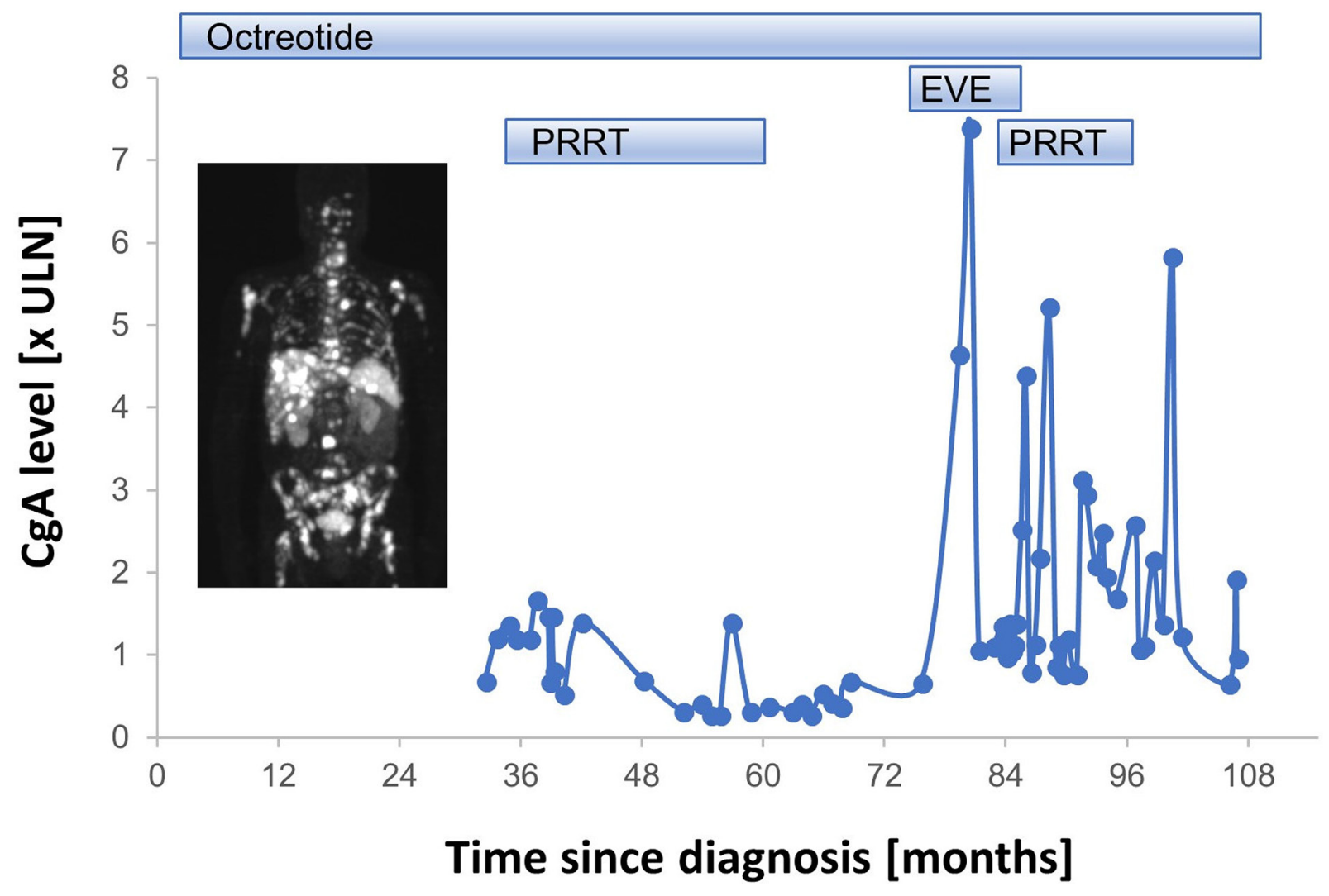

Figure 5: Overview of systemic therapy sequence and tumor marker chromogranin A (CgA) of a patient with metastatic prostatic well differentiated NET (carcinoid). Insert: representative DOTATOC-PET/CT scan showing somatostatin receptor positive lesions. EVE: everolimus; PRRT: peptide receptor radionuclide therapy; ULN: upper limit normal. 
topotecan showed a PR in our analysis. FOLFIRI has been studied in NEC of the gastrointestinal tract [35]. In our study, it showed disease stabilization in first-line, as well as in pretreated patients.

Immune checkpoint blockade has shown promising activity in multiple types of NEC, including small cell lung cancer [36], Merkel cell carcinoma [37, 38], as well as in NEC of the pancreas [39] and cervix [40]. Here we report an extremely good response of NEPC to combined immune checkpoint blockade with ipilimumab and nivolumab.

NEPC is considered to be refractory to ADT [41] and a recent study-cohort showed a high resistance to modern androgen receptor-targeting therapies of up to $73 \%$ [31]. However, 3 of our patients showed a short disease stabilization under enzalutamide and abiraterone. This is in line with several recent reports for large-cell NEPC which have shown expression of androgen receptor as well as sustained responses to conventional ADT [42, 43]. This contributes to the evidence that some androgen dependency might still exist in selected cases, but especially by considering the background of the lineage plasticity model [26], the precise circumstances of the androgen receptor for developing and/or treating a NEPC demands further exploration.

Finally, we reported the first patient with a metastatic well differentiated NET (carcinoid) of the prostate receiving several lines of systemic therapy. He was treated in analogy to NETs of the gastrointestinal tract with octreotide [44], PRRT [45] and everolimus [46]. All systemic therapies were effective in disease stabilization, the patient survived for more than 9 years. Notably, also well differentiated NET have been rarely reported to develop from prostatic adenocarcinoma under ADT [47]; furthermore, somatostatin receptor expression can also be detected in high grade NEPC, indicating that PRRT might be a possible treatment option not only for well differentiated NETs [48].

Our study has several limitations due to its retrospective nature. However, it provides important evidence for potentially active therapeutic regimens in NEPC. PFS seems to be prolonged for carboplatin vs. cisplatin-based regimens, and activity of PE seems lower in patients with a $\mathrm{Ki} 67<55 \%$. The limited prognosis especially of patients with prior history of prostatic adenocarcinoma should be taken into consideration regarding the further clinical decision making for these patients. Most notably, efficacy of FOLFIRI, novel antiandrogens and immune checkpoint blockade should be further evaluated prospectively. Responses should be correlated to clinical parameters as well biomarkers, to further optimize the treatment of this rare disease. Furthermore, the even rarer well differentiated NETs of the prostate (carcinoids) can be treated very successfully in analogy to NETs of the gastrointestinal tract with somatostatin analogues, PRRT and everolimus.

\section{PATIENTS AND METHODS}

We retrospectively reviewed the medical records of all patients with histologically proven NEPC who were treated at the National Center for Tumor Diseases, University Hospital Heidelberg as well as at the Department of Urology, Klinikum Nuremberg, Paracelsus Medical University between 12/2000 and 11/2017. NEPCs with mixed differentiation including an adenocarcinoma component were included at the analysis, as well as well differentiated NETs (carcinoids).

The duration of each therapy as well as the response according to RECIST criteria were recorded, PFS and OS were calculated. PFS was defined as the time span between the start of the respective therapy and the date of progression or death due to any cause. OS was defined on the one hand as the time length between diagnosis of any prostatic malignancy and the date of death from any cause, on the other hand as the time length between NEPC diagnosis and the date of death from any cause.

Statistical analysis was carried out using SPSS ${ }^{\mathrm{TM}}$ for Windows ${ }^{\mathrm{TM}}$ Software V22.0 (SPSS, Chicago, IL, USA). Survival analysis was calculated using the Kaplan-Meier method, and differences in survival were analyzed using the log-rank test. A p-value of $<0.05$ was considered significant.

The trial was approved by the institutional research ethics committee (approval S-428/2014).

\section{Abbreviations}

ACTH: adrenocorticotropic hormone, ADT: androgen deprivation therapy, AURKA: Aurora Kinase A, CgA: chromogranin A, CI: confidence interval, CR: complete response, DIC: disseminated intravascular coagulation, DoR: duration of response, LDH: lactate dehydrogenase, NE: not evaluated, NEC: neuroendocrine carcinoma, NEPC: neuroendocrine carcinoma of the prostate, NET: neuroendocrine tumor, NR: not reached, NSE: neuron-specific enolase, ORR: overall response rate, OS: overall survival, PD: progressive disease, PE: platinum+etoposide, PFS: progression-free survival, PR: partial response, PRRT: peptide receptor radionuclide therapy, PSMA: prostate-specific membrane antigen, SD: stable disease, SIADH: syndrome of inappropriate antidiuretic hormone secretion, SIRT: selective internal radiotherapy, ULN: upper limit normal,

\section{Author contributions}

L.A., F.D. and C.G. designed the study, analyzed and interpreted the data and wrote the manuscript. L.A. and F.D. acquired the data. C.N., E.C.W., A.K.B., C.K., A.K., A.-S.B., D.J., M.H., C.H. and S.P. revised the manuscript for intellectual content. F.D. and C.G. contributed equally. 


\section{CONFLICTS OF INTEREST}

The authors declare no conflict of interest in relation to the work described.

\section{REFERENCES}

1. Zaffuto E, Pompe R, Zanaty M, Bondarenko HD, LeyhBannurah SR, Moschini M, Dell'Oglio P, Gandaglia G, Fossati N, Stabile A, Zorn KC, Montorsi F, Briganti A, et al. Contemporary Incidence and Cancer Control Outcomes of Primary Neuroendocrine Prostate Cancer: A SEER Database Analysis. Clin Genitourin Cancer. 2017; 15:e793-e800. https://doi.org/10.1016/j. clgc.2017.04.006.

2. Wang HT, Yao YH, Li BG, Tang Y, Chang JW, Zhang J. Neuroendocrine Prostate Cancer (NEPC) progressing from conventional prostatic adenocarcinoma: factors associated with time to development of NEPC and survival from NEPC diagnosis-a systematic review and pooled analysis. J Clin Oncol. 2014; 32:3383-90. https://doi.org/10.1200/ JCO.2013.54.3553.

3. Aparicio AM, Harzstark AL, Corn PG, Wen S, Araujo JC, Tu SM, Pagliaro LC, Kim J, Millikan RE, Ryan C, Tannir NM, Zurita AJ, Mathew P, et al. Platinum-based chemotherapy for variant castrate-resistant prostate cancer. Clin Cancer Res. 2013; 19:3621-30. https://doi. org/10.1158/1078-0432.CCR-12-3791.

4. Culine S, El Demery M, Lamy PJ, Iborra F, Avances C, Pinguet F. Docetaxel and cisplatin in patients with metastatic androgen independent prostate cancer and circulating neuroendocrine markers. J Urol. 2007; 178:8448; discussion 8. https://doi.org/10.1016/j.juro.2007.05.044.

5. Flechon A, Pouessel D, Ferlay C, Perol D, Beuzeboc P, Gravis G, Joly F, Oudard S, Deplanque G, Zanetta S, Fargeot P, Priou F, Droz JP, et al. Phase II study of carboplatin and etoposide in patients with anaplastic progressive metastatic castration-resistant prostate cancer (mCRPC) with or without neuroendocrine differentiation: results of the French Genito-Urinary Tumor Group (GETUG) P01 trial. Ann Oncol. 2011; 22:2476-81. https:// doi.org/10.1093/annonc/mdr004.

6. Loriot Y, Massard C, Gross-Goupil M, Di Palma M, Escudier B, Bossi A, Fizazi K. Combining carboplatin and etoposide in docetaxel-pretreated patients with castrationresistant prostate cancer: a prospective study evaluating also neuroendocrine features. Ann Oncol. 2009; 20:703-8. https://doi.org/10.1093/annonc/mdn694.

7. Papandreou CN, Daliani DD, Thall PF, Tu SM, Wang X, Reyes A, Troncoso P, Logothetis CJ. Results of a phase II study with doxorubicin, etoposide, and cisplatin in patients with fully characterized small-cell carcinoma of the prostate. J Clin Oncol. 2002; 20:3072-80. https://doi. org/10.1200/JCO.2002.12.065.
8. Steineck G, Reuter V, Kelly WK, Frank R, Schwartz L, Scher HI. Cytotoxic treatment of aggressive prostate tumors with or without neuroendocrine elements. Acta Oncol. 2002; 41:668-74.

9. Amato RJ, Logothetis CJ, Hallinan R, Ro JY, Sella A, Dexeus FH. Chemotherapy for small cell carcinoma of prostatic origin. J Urol. 1992; 147:935-7.

10. Shimomura T, Kurauchi T, Sakanaka K, Egawa S. Treatment outcome of everolimus against neuroendocrine prostate cancer (NEPC). J Clin Oncol. 2018; 36:365-. https://doi.org/10.1200/JCO.2018.36.6_suppl.365.

11. Beltran H, Danila D, Montgomery B, Szmulewitz R, Vaishampayan U, Armstrong A, Stein M, Hoimes C, Pinski J, Scher H, Puca L, Bareja R, Wong W, et al. A phase 2 study of the aurora kinase A inhibitor alisertib for patients with neuroendocrine prostate cancer (NEPC). Ann Oncol. 2016; 27:LBA29-LBA. https://doi.org/10.1093/annonc/ mdw435.21.

12. Murali R, Kneale K, Lalak N, Delprado W. Carcinoid tumors of the urinary tract and prostate. Arch Pathol Lab Med. 2006; 130:1693-706.

13. Giordano S, Tolonen T, Tolonen T, Hirsimaki S, Kataja V. A pure primary low-grade neuroendocrine carcinoma (carcinoid tumor) of the prostate. Int Urol Nephrol. 2010; 42:683-7. https://doi.org/10.1007/s11255-009-9660-8.

14. Lim KH, Huang MJ, Yang S, Hsieh RK, Lin J. Primary carcinoid tumor of prostate presenting with bone marrow metastases. Urology. 2005; 65:174. https://doi. org/10.1016/j.urology.2004.07.010.

15. Pavel M, O'Toole D, Costa F, Capdevila J, Gross D, Kianmanesh R, Krenning E, Knigge U, Salazar R, Pape UF, Oberg K, Vienna Consensus Conference participants. ENETS Consensus Guidelines Update for the Management of Distant Metastatic Disease of Intestinal, Pancreatic, Bronchial Neuroendocrine Neoplasms (NEN) and NEN of Unknown Primary Site. Neuroendocrinology. 2016; 103:172-85. https://doi.org/10.1159/000443167.

16. Hong MK, Kong J, Namdarian B, Longano A, Grummet J, Hovens CM, Costello AJ, Corcoran NM. Paraneoplastic syndromes in prostate cancer. Nat Rev Urol. 2010; 7:68192. https://doi.org/10.1038/nrurol.2010.186.

17. Garcia-Carbonero R, Sorbye H, Baudin E, Raymond E, Wiedenmann B, Niederle B, Sedlackova E, Toumpanakis C, Anlauf M, Cwikla JB, Caplin M, O'Toole D, Perren A, et al. ENETS Consensus Guidelines for High-Grade Gastroenteropancreatic Neuroendocrine Tumors and Neuroendocrine Carcinomas. Neuroendocrinology. 2016; 103:186-94. https://doi.org/10.1159/000443172.

18. Sorbye H, Welin S, Langer SW, Vestermark LW, Holt N, Osterlund P, Dueland S, Hofsli E, Guren MG, Ohrling K, Birkemeyer E, Thiis-Evensen E, Biagini M, et al. Predictive and prognostic factors for treatment and survival in 305 patients with advanced gastrointestinal neuroendocrine carcinoma (WHO G3): the NORDIC NEC study. Ann 
Oncol. 2013; 24:152-60. https://doi.org/10.1093/annonc/ $\operatorname{mds} 276$.

19. Heetfeld M, Chougnet CN, Olsen IH, Rinke A, Borbath I, Crespo G, Barriuso J, Pavel M, O'Toole D, Walter T, other Knowledge Network members. Characteristics and treatment of patients with G3 gastroenteropancreatic neuroendocrine neoplasms. Endocr Relat Cancer. 2015; 22:657-64. https://doi.org/10.1530/ERC-15-0119.

20. Velayoudom-Cephise FL, Duvillard P, Foucan L, Hadoux J, Chougnet CN, Leboulleux S, Malka D, Guigay J, Goere D, Debaere T, Caramella C, Schlumberger M, Planchard D, et al. Are G3 ENETS neuroendocrine neoplasms heterogeneous? Endocr Relat Cancer. 2013; 20:649-57. https://doi.org/10.1530/ERC-13-0027.

21. Welin S, Sorbye H, Sebjornsen S, Knappskog S, Busch C, Oberg K. Clinical effect of temozolomide-based chemotherapy in poorly differentiated endocrine carcinoma after progression on first-line chemotherapy. Cancer. 2011; 117:4617-22. https://doi.org/10.1002/cncr.26124.

22. Hadoux J, Malka D, Planchard D, Scoazec JY, Caramella C, Guigay J, Boige V, Leboulleux S, Burtin P, Berdelou A, Loriot Y, Duvillard P, Chougnet CN, et al. Post-firstline FOLFOX chemotherapy for grade 3 neuroendocrine carcinoma. Endocr Relat Cancer. 2015; 22:289-98. https:// doi.org/10.1530/ERC-15-0075.

23. Katou M, Soga N, Onishi T, Arima K, Sugimura Y. Small cell carcinoma of the prostate treated with amrubicin. Int J Clin Oncol. 2008; 13:169-72. https://doi.org/10.1007/ s10147-007-0702-x.

24. Beltran H, Rickman DS, Park K, Chae SS, Sboner A, MacDonald TY, Wang Y, Sheikh KL, Terry S, Tagawa ST, Dhir R, Nelson JB, de la Taille A, et al. Molecular characterization of neuroendocrine prostate cancer and identification of new drug targets. Cancer Discov. 2011; 1:487-95. https://doi.org/10.1158/2159-8290.CD-11-0130.

25. Chen R, Dong X, Gleave M. Molecular model for neuroendocrine prostate cancer progression. BJU Int. 2018; 122:560-70. https://doi.org/10.1111/bju.14207.

26. Rickman DS, Beltran H, Demichelis F, Rubin MA. Biology and evolution of poorly differentiated neuroendocrine tumors. Nat Med. 2017; 23:1-10. https://doi.org/10.1038/ nm.4341.

27. Beltran H, Eng K, Mosquera JM, Sigaras A, Romanel A, Rennert H, Kossai M, Pauli C, Faltas B, Fontugne J, Park K, Banfelder J, Prandi D, et al. Whole-Exome Sequencing of Metastatic Cancer and Biomarkers of Treatment Response. JAMA Oncol. 2015; 1:466-74. https://doi.org/10.1001/ jamaoncol.2015.1313.

28. Kanayama M, Hayano T, Koebis M, Maeda T, Tabe Y, Horie $\mathrm{S}$, Aiba A. Hyperactive mTOR induces neuroendocrine differentiation in prostate cancer cell with concurrent up-regulation of IRF1. Prostate. 2017; 77:1489-98. https:// doi.org/10.1002/pros.23425.
29. Hsieh TC, Lin CY, Lin HY, Wu JM. AKT/mTOR as Novel Targets of Polyphenol Piceatannol Possibly Contributing to Inhibition of Proliferation of Cultured Prostate Cancer Cells. ISRN Urol. 2012; 2012:272697. https://doi. org/10.5402/2012/272697.

30. Zhang W, Liu B, Wu W, Li L, Broom BM, Basourakos SP, Korentzelos D, Luan Y, Wang J, Yang G, Park S, Azad AK, Cao X, et al. Targeting the MYCN-PARP-DNA Damage Response Pathway in Neuroendocrine Prostate Cancer. Clin Cancer Res. 2018; 24:696-707. https://doi. org/10.1158/1078-0432.CCR-17-1872.

31. Aggarwal R, Huang J, Alumkal JJ, Zhang L, Feng FY, Thomas GV, Weinstein AS, Friedl V, Zhang C, Witte ON, Lloyd P, Gleave M, Evans CP, et al. Clinical and Genomic Characterization of Treatment-Emergent Small-Cell Neuroendocrine Prostate Cancer: A Multi-institutional Prospective Study. J Clin Oncol. 2018; 36:2492-503. https://doi.org/10.1200/JCO.2017.77.6880.

32. von Pawel J, Schiller JH, Shepherd FA, Fields SZ, Kleisbauer JP, Chrysson NG, Stewart DJ, Clark PI, Palmer MC, Depierre A, Carmichael J, Krebs JB, Ross G, et al. Topotecan versus cyclophosphamide, doxorubicin, and vincristine for the treatment of recurrent small-cell lung cancer. J Clin Oncol. 1999; 17:658-67.

33. Apostolidis L, Bergmann F, Jager D, Winkler EC. Efficacy of topotecan in pretreated metastatic poorly differentiated extrapulmonary neuroendocrine carcinoma. Cancer Med. 2016; 5:2261-7. https://doi.org/10.1002/cam4.807.

34. Olsen IH, Knigge U, Federspiel B, Hansen CP, Skov A, Kjaer A, Langer SW. Topotecan monotherapy in heavily pretreated patients with progressive advanced stage neuroendocrine carcinomas. J Cancer. 2014; 5:628-32. https://doi.org/10.7150/jca.9409.

35. Hentic O, Hammel P, Couvelard A, Rebours V, Zappa M, Palazzo M, Maire F, Goujon G, Gillet A, Levy P, Ruszniewski P. FOLFIRI regimen: an effective secondline chemotherapy after failure of etoposide-platinum combination in patients with neuroendocrine carcinomas grade 3. Endocr Relat Cancer. 2012; 19:751-7. https://doi. org/10.1530/ERC-12-0002.

36. Antonia SJ, Lopez-Martin JA, Bendell J, Ott PA, Taylor M, Eder JP, Jager D, Pietanza MC, Le DT, de Braud F, Morse MA, Ascierto PA, Horn L, et al. Nivolumab alone and nivolumab plus ipilimumab in recurrent small-cell lung cancer (CheckMate 032): a multicentre, open-label, phase 1/2 trial. Lancet Oncol. 2016; 17:883-95. https://doi. org/10.1016/S1470-2045(16)30098-5.

37. Kaufman HL, Russell J, Hamid O, Bhatia S, Terheyden P, D'Angelo SP, Shih KC, Lebbe C, Linette GP, Milella M, Brownell I, Lewis KD, Lorch JH, et al. Avelumab in patients with chemotherapy-refractory metastatic Merkel cell carcinoma: a multicentre, single-group, open-label, phase 2 trial. Lancet Oncol. 2016; 17:1374-85. https://doi. org/10.1016/S1470-2045(16)30364-3. 
38. Nghiem PT, Bhatia S, Lipson EJ, Kudchadkar RR, Miller NJ, Annamalai L, Berry S, Chartash EK, Daud A, Fling SP, Friedlander PA, Kluger HM, Kohrt HE, et al. PD-1 Blockade with Pembrolizumab in Advanced Merkel-Cell Carcinoma. N Engl J Med. 2016; 374:2542-52. https://doi. org/10.1056/NEJMoa1603702.

39. Ugwu JK, Nwanyanwu C, Shelke AR. Dramatic Response of a Metastatic Primary Small-Cell Carcinoma of the Pancreas to a Trial of Immunotherapy with Nivolumab: A Case Report. Case Rep Oncol. 2017; 10:720-5. https://doi. org/10.1159/000479315.

40. Paraghamian SE, Longoria TC, Eskander RN. Metastatic small cell neuroendocrine carcinoma of the cervix treated with the PD-1 inhibitor, nivolumab: a case report. Gynecol Oncol Res Pract. 2017; 4:3. https://doi.org/10.1186/ s40661-017-0038-9.

41. Moore SR, Reinberg Y, Zhang G. Small cell carcinoma of prostate: effectiveness of hormonal versus chemotherapy. Urology. 1992; 39:411-6.

42. Acosta-Gonzalez G, Qin J, Wieczorek R, Melamed J, Deng FM, Zhou M, Makarov D, Ye F, Pei Z, Pincus MR, Lee P. De novo large cell neuroendocrine carcinoma of the prostate, case report and literature review. Am J Clin Exp Urol. 2014; 2:337-42.

43. Azad AA, Jones EC, Chi KN. Metastatic large-cell neuroendocrine prostate carcinoma: successful treatment with androgen deprivation therapy. Clin Genitourin Cancer. 2014; 12:e151-3. https://doi.org/10.1016/j. clgc.2014.03.006.
44. Rinke A, Muller HH, Schade-Brittinger C, Klose KJ, Barth P, Wied M, Mayer C, Aminossadati B, Pape UF, Blaker M, Harder J, Arnold C, Gress T, et al. Placebo-controlled, double-blind, prospective, randomized study on the effect of octreotide LAR in the control of tumor growth in patients with metastatic neuroendocrine midgut tumors: a report from the PROMID Study Group. J Clin Oncol. 2009; 27:4656-63. https://doi.org/10.1200/JCO.2009.22.8510.

45. Strosberg J, El-Haddad G, Wolin E, Hendifar A, Yao J, Chasen B, Mittra E, Kunz PL, Kulke MH, Jacene H, Bushnell D, O'Dorisio TM, Baum RP, et al. Phase 3 Trial of (177)Lu-Dotatate for Midgut Neuroendocrine Tumors. N Engl J Med. 2017; 376:125-35. https://doi.org/10.1056/ NEJMoa1607427.

46. Yao JC, Fazio N, Singh S, Buzzoni R, Carnaghi C, Wolin E, Tomasek J, Raderer M, Lahner H, Voi M, Pacaud LB, Rouyrre N, Sachs C, et al. Everolimus for the treatment of advanced, non-functional neuroendocrine tumours of the lung or gastrointestinal tract (RADIANT-4): a randomised, placebo-controlled, phase 3 study. Lancet. 2016; 387:96877. https://doi.org/10.1016/S0140-6736(15)00817-X.

47. Gilani S, Guo CC, Li-Ning EM, Pettaway C, Troncoso P. Transformation of prostatic adenocarcinoma to welldifferentiated neuroendocrine tumor after hormonal treatment. Hum Pathol. 2017; 64:186-90. https://doi. org/10.1016/j.humpath.2017.01.006.

48. Gofrit ON, Frank S, Meirovitz A, Nechushtan H, Orevi M. PET/CT With 68Ga-DOTA-TATE for Diagnosis of Neuroendocrine: Differentiation in Patients With CastrateResistant Prostate Cancer. Clin Nucl Med. 2017; 42:1-6. https://doi.org/10.1097/RLU.0000000000001424. 